\title{
Flurbiprofen suppresses the inflammation, proliferation, invasion and migration of colorectal cancer cells via COX2
}

\author{
XIAOBO WANG $^{1},{\text { XUXING } \text { YE }^{2} \text {, YILI ZHANG }}^{3}$ and FENG JI ${ }^{1}$ \\ ${ }^{1}$ Department of Gastroenterology, The First Affiliated Hospital, College of Medicine, Zhejiang University, \\ Hangzhou, Zhejiang 310003; ${ }^{2}$ Traditional Medicine Center; ${ }^{3}$ Physical Examination Center, \\ Jinhua Hospital, Zhejiang University, Jinhua, Zhejiang 321000, P.R. China
}

Received February 17, 2020; Accepted July 2, 2020

DOI: 10.3892/ol.2020.11993

\begin{abstract}
Colorectal cancer is an aggressive disease with a poor prognosis and low survival rate at the advanced stage, therefore new innovative targets are urgently required. Flurbiprofen has been reported to exhibit therapeutic effects in other types of cancer, such as esophageal cancer, breast cancer and colorectal cancer. Therefore, the present study aimed to investigate the function of flurbiprofen in colorectal cancer. SW620 colorectal cancer cells were treated with different concentrations of flurbiprofen to determine the optimum concentration. Subsequently, COX2 expression affected by flurbiprofen was tested using western blotting, reverse transcription-quantitative PCR and immunofluorescence. Enzyme-linked immunosorbent assay was used to determine the levels of tumor necrosis factor- $\alpha$, interleukin (IL)-6 and IL-1 $\beta$. Cell Counting Kit-8, colony formation and flow cytometry assays were used to assess the proliferation and apoptosis of SW620 cells in various groups. Western blotting was performed to investigate the expression of proliferation-, apoptosis- and migration-related proteins after different treatments. Wound healing and Transwell assays were performed to measure the invasion and migration of colorectal cancer cells, respectively. The results demonstrated that flurbiprofen inhibited colorectal cancer cell proliferation. Furthermore, it was identified that flurbiprofen inhibited the expression of COX2. Notably, flurbiprofen suppressed the expression of inflammatory factors by inhibiting COX2 . Moreover, flurbiprofen inhibited the proliferation, invasion and migration of colorectal cancer cells by inhibiting COX2. In conclusion, the present study revealed that flurbiprofen inhibited $\mathrm{COX} 2$ expression in colorectal cancer, and affected the proliferation, invasion, migration and apoptosis of colorectal cancer cells. These results expand the understanding of the
\end{abstract}

Correspondence to: Dr Feng Ji, Department of Gastroenterology, The First Affiliated Hospital, College of Medicine, Zhejiang University, 79 Qingchun Road, Hangzhou, Zhejiang 310003, P.R. China

E-mail:1189005@zju.edu.cn

Key words: flurbiprofen, cyclooxygenase 2, colorectal cancer function of COX2 in colorectal cancer and the effect of flurbiprofen on COX2 expression.

\section{Introduction}

Colorectal cancer is a common gastrointestinal malignancy with a high mortality rate, originating from the mucosal epithelium and glands of the large intestine (1). Colorectal cancer is currently the third most common form of cancer and the second most common cause of mortality globally as reported by research conducted in 2019 (2). In the early stage of the disease, the tumor can be effectively treated through minimally invasive surgery and radical surgery, which avoids the inconvenience of radiotherapy and chemotherapy, or even by implantation of an artificial sphincter $(3,4)$. However, due to the occurrence of distant metastasis, such as lymph node metastasis and liver metastasis, the treatment options for numerous patients are poor, resulting in high recurrence rates and low survival rates, which markedly affects the life quality of patients $(5,6)$. The exact pathogenesis of colorectal cancer remains unclear; however, a large number of studies have reported that the pathogenesis of colorectal cancer involves multiple genes and is a multi-stage process $(7,8)$. Therefore, it is necessary to search for treatment methods and drugs for colorectal cancer, which may help to improve the therapeutic effect of colorectal cancer treatments, prolong the survival period and improve the quality of life $(7,9,10)$.

Flurbiprofen is a commonly used non-steroidal anti-inflammatory drug; it is a non-selective cyclooxygenase (COX) inhibitor and has a high affinity for immune organs $(11,12)$. Flurbiprofen is commonly used to treat inflammatory diseases, including osteoarthritis and rheumatoid arthritis, as well as pain control during surgery (13). Flurbiprofen has been shown to significantly reduce postoperative pain scores and improve post-chemotherapy immunity in patients with cancer $(14,15)$. Flurbiprofen therapy can promote the natural circulation of dendritic cells in patients with esophageal squamous cell carcinoma and inhibit the rise of IL-10 and TGF- $\beta$ (16). In addition, flurbiprofen increases the postoperative IL- 8 expression in patients with esophageal cancer, reduces the pain score and improves the oxidation level (17). Furthermore, flurbiprofen inhibits the activation and aggregation of leukocytes in patients with a tumor and reduces the formation of venous 
embolism (18). Additionally, flurbiprofen inhibits the increase of TNF- $\alpha$ and IL-1 $\beta$ in patients with breast cancer $(19,20)$. Toxicity studies on breast and lung cancer cells have demonstrated that anti-inflammation can damage the integrity and permeability of cell membrane structures, thereby inhibiting the growth and proliferation of cells $(21,22)$. Flurbiprofen has been reported to reduce IL-6 in patients with colorectal cancer, increase IL-2 secretion and reduce surgical complications (23). However, to the best of our knowledge, the direct effect of flurbiprofen on colorectal cancer and its mechanism remain unknown. Therefore, the present study investigated the effect of flurbiprofen on the proliferation and migration of colorectal cancer cells by regulating COX2.

At present, there are three reported COX isozymes, COX1, COX2 and COX3, which are known to regulate fever and pain (24). COX2 is an inducible enzyme that is mainly distributed on the cell nuclear membrane (25). COX2 is predominantly expressed in the kidney and brain at general physiological conditions, and remains silent in other tissues (26). The expression of COX2 changes only after various stimulations (27). It has been reported that COX 2 is highly expressed in colorectal cancer (28); however, to the best of our knowledge, the function of COX 2 in colorectal cancer and the mechanism of its function remain unclear. Therefore, further studies are required to clarify the role of COX2 in colorectal cancer. Additionally, inhibitors of COX2 should be investigated to potentially provide a new therapeutic target for colorectal cancer.

\section{Materials and methods}

Cell culture. Human SW620 colorectal cancer cells were cultured in DMEM (Hyclone; GE Healthcare Life Sciences) containing 10\% FBS (Gibco; Thermo Fisher Scientific Inc.) and $1 \%$ penicillin/streptomycin (Invitrogen; Thermo Fisher Scientific Inc.), in a cell culture chamber at $37^{\circ} \mathrm{C}$ with $5 \% \mathrm{CO}_{2}$. Following counting and inoculation in plates, the cells grew to the required cell density of $80-90 \%$ and were treated accordingly. For determining the optimal concentration of flurbiprofen for treating SW620 cells; 2, 4, 10 and $20 \mathrm{nM}$ of flurbiprofen were used for 12,24 or $48 \mathrm{~h}$ at $37^{\circ} \mathrm{C}$. Cells treated with $0.1 \%$ DMSO were the control group.

Cell transfection. A total of $3 \times 10^{5}$ SW620 cells (cell density, $5 \times 10^{4}$ cells/well) were plated in a 6 -well plate, and transfection with an overexpression plasmid was performed when the cells grew to $70-80 \%$ density. During transfection, the original cell culture medium was removed and the cells were cultured in medium without serum and antibiotics. The overexpression plasmid pcDNA-COX2 (20 nM) and negative control pcDNA $(1 \mu \mathrm{g})$ from Shanghai Genechem Co., Ltd., were diluted with $125 \mu 1$ Opti-MEM medium (Gibco; Thermo Fisher Scientific Inc.), and Lipofectamine 2000 (Invitrogen; Thermo Fisher Scientific, Inc.) was diluted with $125 \mu 1$ Opti-MEM medium at room temperature for $5 \mathrm{~min}$. These were then mixed for 15 min before addition to the cell culture medium. The liquid was changed after 4-6 h, and the cells were collected for further experiments after 24-48 h.

RNA extraction and reverse transcription-quantitative $P C R$ $(R T-q P C R)$. RNA was extracted from the treated cells using
TRIzol (Invitrogen; Thermo Fisher Scientific Inc.). RT was performed with PrimeScript ${ }^{\mathrm{TM}}$ RT Reagent kit with gDNA Eraser (Takara Bio, Inc.) at $37^{\circ} \mathrm{C}$ for $15 \mathrm{~min}$ and at $98^{\circ} \mathrm{C}$ for 5 min. qPCR was performed using SYBR reagent (Invitrogen; Thermo Fisher Scientific, Inc.) according to the manufacturer's protocol. Thermocycling conditions were as follows: $95^{\circ} \mathrm{C}$ for $3 \mathrm{~min}, 40$ cycles of $95^{\circ} \mathrm{C}$ for $5 \mathrm{sec}$ followed by $60^{\circ} \mathrm{C}$ for $30 \mathrm{sec}$. GAPDH was used as the internal reference and quantification was performed using the $2^{-\Delta \Delta \mathrm{Cq}}$ method (29). The primer sequences used were: COX2 forward, 5'-ATCATAAGCGAG GGCCAGCT-3' and reverse, 5'-AAGGCGCAGTTTACGCTG TC-3'; GAPDH forward, 5'-GACAGTCAGCCGCATCTT CT-3' and reverse, 5'-GCGCCCAATACGACCAAATC-3'.

Cell Couniting Kit-8 (CCK-8) assay. SW620 cells were seeded into a 96 -well plate $24 \mathrm{~h}$ post-transfection at a density of 3,000 cells/well. CCK-8 was used to assess the cell viability at 12, 24 and $48 \mathrm{~h}$. A total of $10 \mu \mathrm{l} \mathrm{CCK-8} \mathrm{solution} \mathrm{(Dojindo} \mathrm{Molecular}$ Technologies) was added to each well and the cells were cultured for a further $4 \mathrm{~h}$ according to the manufacturer's protocol. An enzyme-linked immune detector was used to measure the absorbance value of each well at a wavelength of $450 \mathrm{~nm}$.

Western blot analysis. The treated cells were lysed with RIPA lysis buffer (cat. no. 9806; Cell Signaling Technology, Inc.), placed in a $1.5-\mathrm{ml} \mathrm{EP}$ tube, and centrifuged at $4^{\circ} \mathrm{C}$ and $12,000 \times \mathrm{g}$ for $10 \mathrm{~min}$. The supernatant was isolated and the protein concentration was measured using a BCA Protein assay kit (cat. no. 23227; Thermo Fisher Scientific, Inc.). Next, the protein was denatured at $100^{\circ} \mathrm{C}$ for $10 \mathrm{~min}$ with $10 \%$ SDS-polyacrylamide gel electrophoresis, and $25 \mu \mathrm{g}$ protein sample per lane was separated. Following membrane transfer, the PVDF membrane was incubated with non-fat milk for $30 \mathrm{~min}$ at room temperature, incubated with primary antibody for $4^{\circ} \mathrm{C}$ overnight, and washed with TBS containing $0.05 \%$ Tween-20 (TBST) 3 times for $10 \mathrm{~min}$ each time. Primary antibodies were all purchased from Abcam and were against COX2 (1:1,000; cat. no. ab179800), cyclin E (1:1,000; cat. no. ab33911), CDK2 (1:1,000; cat. no. ab32147), p21 (1:1,000; cat. no. ab109520), Bcl-2 (1:5,000; cat. no. ab196495), Bax (1:1,000; cat. no. ab199677), cleaved caspase-3 (1:500; cat. no. ab49822), caspase-3 (1:5,000; cat. no. ab32351), MMP2 (1:1,000; cat. no. ab181286), MMP9 (1:1,000; cat. no. ab137867) and GAPDH (1:3,000; cat. no. ab9485). The membrane was then incubated with horseradish peroxidase-conjugated secondary antibody goat anti-rabbit IgG (1:10,000; cat. no. ab205718; Abcam) at room temperature for $2 \mathrm{~h}$ and washed with $1 \mathrm{X}$ TBST three times for $10 \mathrm{~min}$ each time. Enhanced chemiluminescence reagents (Beyotime Institute of Biotechnology) was added for visualization and next quantified with Quantity One version 4.1 software (Bio-Rad Laboratories Inc.).

Immunofluorescence assay. In the immunofluorescence assay, changes in COX2 expression were examined. SW620 cells were subjected to fixation with $4 \%$ paraformaldehyde for $15 \mathrm{~min}$ at room temperature and permeabilization with $0.5 \%$ Triton X-100. Subsequently, 5\% normal goat serum (PH0424; Scientific Phygene) was used to block cells for $20 \mathrm{~min}$ at $37^{\circ} \mathrm{C}$, followed by incubation overnight at $4^{\circ} \mathrm{C}$ with anti-COX2 $(1: 1,000$; cat. no. 4842; Cell Signaling Technology, Inc.). Subsequently, 
A

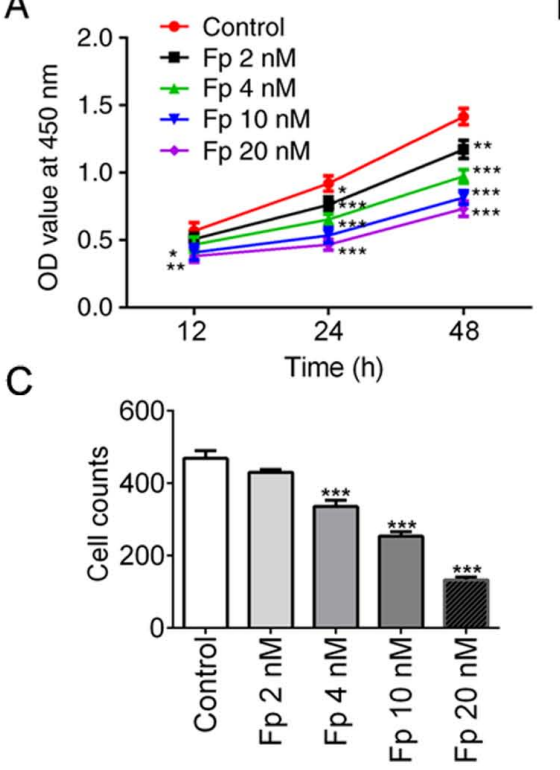

B

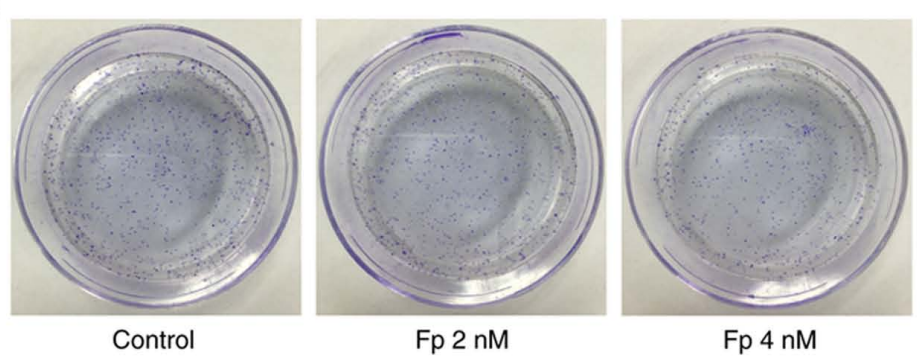

Figure 1. Fp inhibits colorectal cancer cell proliferation. (A) Cell viability of SW620 cells treated with Fp were evaluated by Cell Counting Kit-8 assay. ${ }^{*} \mathrm{P}<0.05,{ }^{* *} \mathrm{P}<0.01,{ }^{* * *} \mathrm{P}<0.001$ vs. control. (B and $\mathrm{C}$ ) Colony formation ability was explored by colony formation assay. ${ }^{* * *} \mathrm{P}<0.001$ vs. control. Fp, flurbiprofen; OD, optical density.

the cells were probed with an Alexa Fluor 488 labeled-goat anti-rabbit IgG (1:500; cat. no. A0423; Beyotime Institute of Biotechnology) for nearly $2 \mathrm{~h}$ at room temperature. Nuclei were counterstained using DAPI (Invitrogen; Thermo Fisher Scientific Inc.) at room temperature for $5 \mathrm{~min}$, and images were captured using a fluorescence microscope (magnification, x20).

ELISA. Human IL-6 Quantikine (cat. no. D6050), human IL-1 $\beta$ Quantikine (cat. no. DLB50) and human TNF- $\alpha$ Quantikine ELISA kits (cat. no. DTA00D) (all R\&D Systems, Inc.) were used to measure the levels of IL-6, IL- $1 \beta$ and TNF- $\alpha$ in cell supernatants of SW620 according to the manufacturer's protocols.

Colony formation assay. A total of 200 SW620 cells/well were plated in 12-well plates and cultured in DMEM with $10 \%$ FBS for 14 days. PBS was used to wash the cells twice, and then the cells were fixed with methanol for $\sim 10 \mathrm{~min}$ at room temperature. Following fixation, the cells were washed twice with PBS, stained with crystal violet for $30 \mathrm{~min}$ at room temperature, and then washed with double-distilled water. The number of the colonies $\geq 50$ was counted using the naked eye.

Flow cytometry. For flow cytometric analysis, FITC Annexin V Apoptosis Detection kit (Guangzhou RiboBio Co., Ltd.) was used. After $30 \mathrm{~min}$ of culture in the dark, SW620 cells (1x $10^{5}$ cells/well) in $200 \mu \mathrm{l}$ of binding buffer were mixed with $5 \mu \mathrm{l}$ of propidium iodide (PI) for $15 \mathrm{~min}$ at $4^{\circ} \mathrm{C}$ and apoptosis was detected using a BD Accuri C6 Plus personal flow cytometer (Becton, Dickinson and Company) and analyzed using FlowJo version 10 software (Tree Star, Inc.).

Wound healing assay. Cell migratory ability was analyzed using a wound healing assay. Cells in control, Fp $10 \mathrm{nM}$, Fp $10 \mathrm{nM}+$ pcDNA and Fp $10 \mathrm{nM}+$ pcDNA-COX2 groups were cultured and then a $5-\mathrm{mm}$ horizontal scratch was made using a pipette tip. Subsequently, cells were incubated for 1 day at $37^{\circ} \mathrm{C}$ in a serum-free medium, and the gap width was assessed and recorded at 0 and $24 \mathrm{~h}$ using a light microscope (Leica Microsystems) with magnification, x100. Relative migration rate was calculated as the percentage of wound healing.

Transwell invasion assay. The cell invasion assay was performed using 24-well Transwell inserts (Corning, Inc.) pre-coated with Matrigel (BD Biosciences at room temperature for 15-30 min. Following cell suspension in $200 \mathrm{ml}$ serum-free DMEM, cells $\left(1 \times 10^{5}\right)$ were added to the upper chamber and medium supplemented with $10 \%$ FBS was placed in the bottom chamber. Subsequently, cells on the upper surface were removed, and cells on the bottom surface were fixed and stained with crystal violet at room temperature for $20 \mathrm{~min}$. Cell numbers in five random fields were calculated using a light microscope (Nikon Corporation) with magnification, x100.

Statistical analysis. Data obtained from triplicated independent experiments were presented as mean \pm standard deviation (SD). Two-sided unpaired Student's t-test was used to assess the differences between two groups. For multiple groups, one-way ANOVA followed by Tukey's post hoc test was used. GraphPad Prism 5.0 software (GraphPad Software, Inc.) and SPSS 13.0 software (SPSS, Inc.) were employed to analyze data. $\mathrm{P}<0.05$ was considered to indicate a statistically significant difference.

\section{Results}

Flurbiprofen inhibits colorectal cancer cell proliferation. To evaluate the impact of flurbiprofen on colorectal cancer, SW620 cells were treated with different concentrations of flurbiprofen $(2,4,10$ and $20 \mathrm{nM})$ and the cell proliferation was assessed by a CCK-8 assay at 12, 24 and $48 \mathrm{~h}$, respectively. As expected, flurbiprofen significantly decreased SW620 cell 


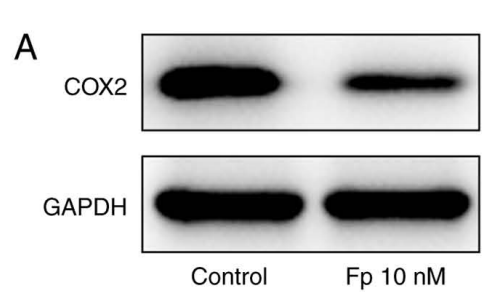

C
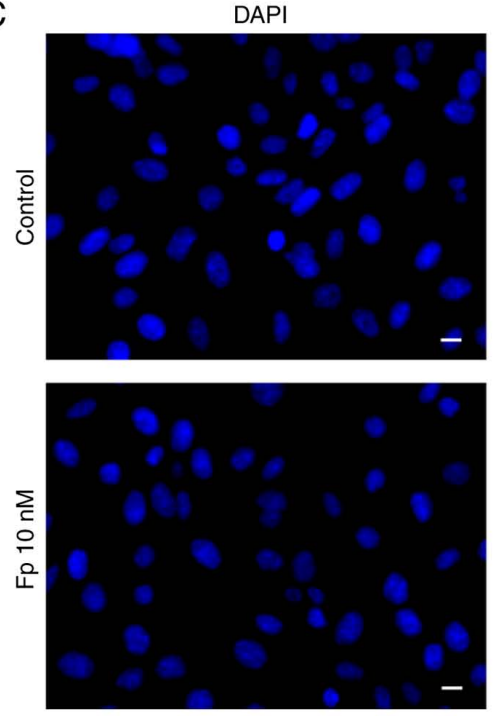
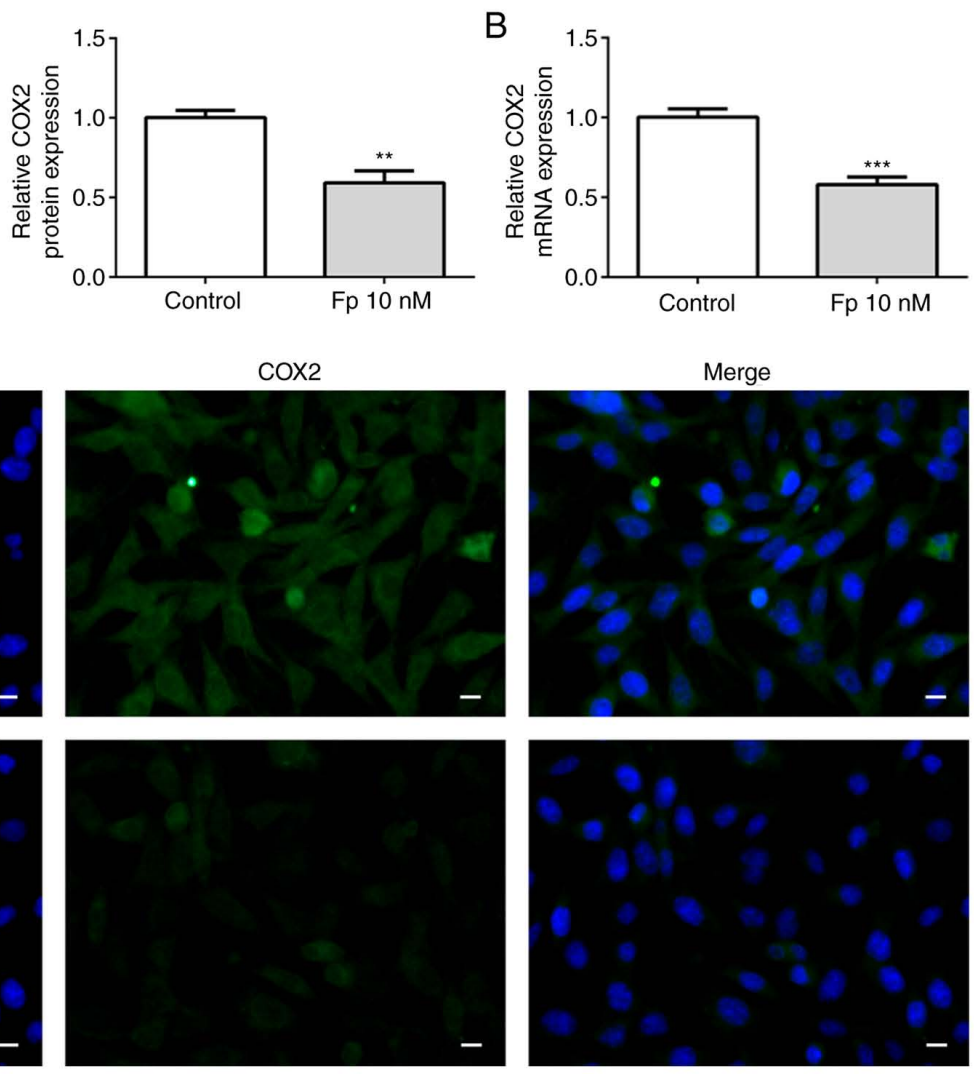

Figure 2. Fp inhibits COX2 expression. COX2 (A) protein and (B) mRNA expression in control and Fp-treated SW620 cells was analyzed via western blot analysis and reverse transcription-quantitative PCR. (C) An immunofluorescence assay detected the changes of COX2 expression in SW620 cells in response to Fp. Scale bar, $50 \mu \mathrm{m} .{ }^{* *} \mathrm{P}<0.01,{ }^{* * *} \mathrm{P}<0.001$ vs. control. Fp, flurbiprofen; COX2, cyclooxygenase 2.

proliferation in a concentration- and time-dependent manner (Fig. 1A). In the colony formation assay, it was observed that with an increasing concentration of flurbiprofen, the number of colonies gradually decreased (Fig. 1B-C). When the cells were treated with $10 \mathrm{nM}$ flurbiprofen, the cell viability (at $24 \mathrm{~h}$ ) and colony formation ability were reduced to $\sim 50 \%$ of the levels observed in the control group, therefore $10 \mathrm{nM}$ flurbiprofen was selected for the following experiments. These data suggest that flurbiprofen inhibited colorectal cancer cell proliferation.

Flurbiprofen decreases COX2 expression. It has been reported that flurbiprofen is a non-selective COX inhibitor (30). Therefore, the present study aimed to evaluate whether flurbiprofen has an effect on COX2 in SW620 colorectal cancer cells. Western blotting was used to measure the protein level of COX2 after cells were treated with $10 \mathrm{nM}$ flurbiprofen (Fig. 2A). In addition, RT-qPCR was used to assess the mRNA level of COX2 following treatment with $10 \mathrm{nM}$ flurbiprofen (Fig. 2B). As expected, the protein and mRNA levels of COX2 were significantly decreased. To confirm this result, an immunofluorescence assay with SW620 cells treated with $10 \mathrm{nM}$ flurbiprofen or DMSO was performed (Fig. 2C). The fluorescence intensity of $\mathrm{COX} 2$ was markedly reduced when treated with $10 \mathrm{nM}$ flurbiprofen. The data confirmed that flurbiprofen decreased COX 2 expression.

Flurbiprofen inhibits the expression of inflammatory factors by inhibiting COX2. COX2 was overexpressed in SW620 cells, and western blotting and RT-qPCR were used to assess transfection efficiency (Fig. 3A and B). It has been reported that COX2 is a highly expressed inflammatory factor (31). Thus, the present study investigated whether flurbiprofen inhibits the expression of inflammatory factors by inhibiting COX2. ELISA was used to measure the levels of TNF- $\alpha$, IL- $1 \beta$ and IL-6. As presented in the Fig. 3C, the levels of TNF- $\alpha$, IL-1 $\beta$ and IL-6 were significantly downregulated in cells treated with flurbiprofen compared with control cells. However, when cells were co-treated with flurbiprofen and COX2 overexpression plasmid, the levels of TNF- $\alpha$, IL- $1 \beta$ and IL- 6 were significantly higher compared with in cells treated with flurbiprofen alone. These results suggested that flurbiprofen inhibited the expression of inflammatory factors via repression of COX2.

Flurbiprofen inhibits the proliferation of colorectal cancer cells by inhibiting COX2. To determine whether flurbiprofen has an effect on colorectal cancer cell proliferation, a colony formation assay was performed, and it was identified that transfection of COX2 overexpression plasmid reversed the suppressed cell colony formation ability by flurbiprofen alone (Fig. 4A-B). Subsequently, western blotting was used to evaluate the changes of proliferation-associated proteins, including cyclin E, cyclin-dependent kinase 2 (CDK2) and p21. The results demonstrated that in cells treated with flurbiprofen, the expression levels of cyclin E and CDK2 were significantly decreased, and the expression of p21 was significantly increased. However, in cells co-treated with flurbiprofen and COX2 overexpression plasmid, the flurbiprofen-induced expression level changes of cyclin E, CDK2 and p21 were significantly reversed (Fig. 4C). 

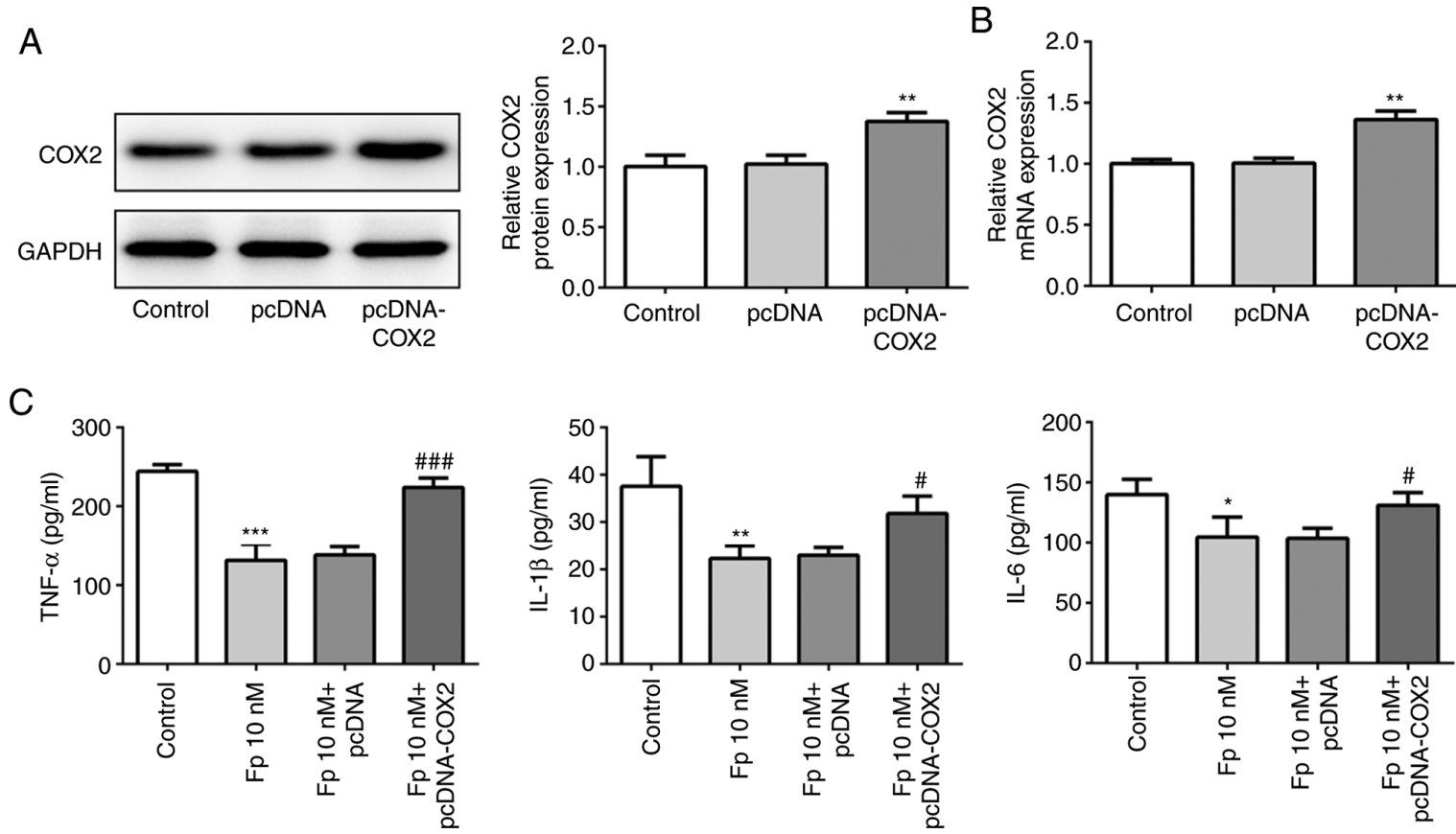

Figure 3. Fp restrains inflammation. (A) Western blot analysis and (B) reverse transcription-quantitative PCR were used to measure COX2 protein and mRNA expression levels. ${ }^{* *} \mathrm{P}<0.01$ vs. pcDNA. (C) ELISA was used to estimate the levels of the inflammatory factors TNF- $\alpha$, IL- $1 \beta$ and IL-6 following COX2 overexpression and/or treatment with Fp. ${ }^{*} \mathrm{P}<0.05,{ }^{* * *} \mathrm{P}<0.01,{ }^{* * *} \mathrm{P}<0.001$ vs. control. ${ }^{\#} \mathrm{P}<0.05,{ }^{\# \# "} \mathrm{P}<0.001$ vs. Fp $10 \mathrm{nM}+$ pcDNA. Fp, flurbiprofen; COX2, cyclooxygenase 2 .

A
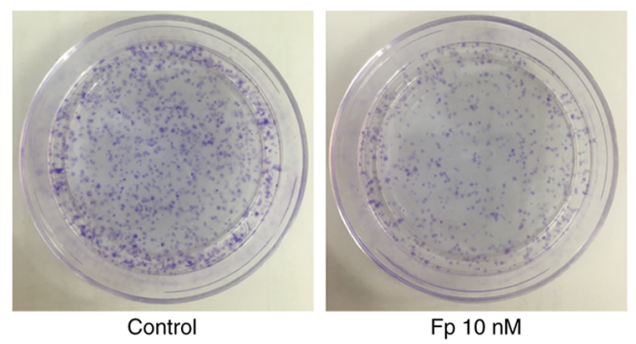

C

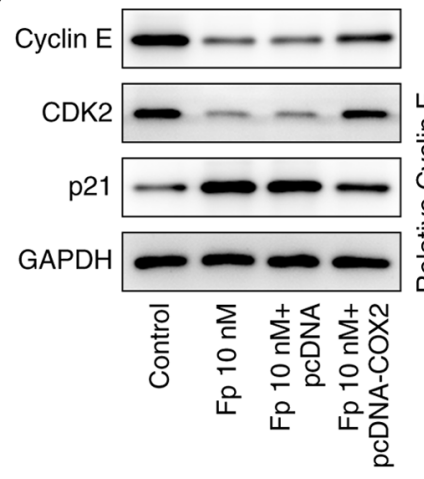

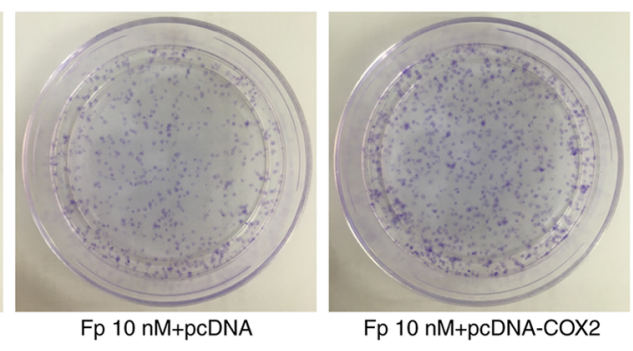

Fp 10 nM+pcDNA-COX2

B
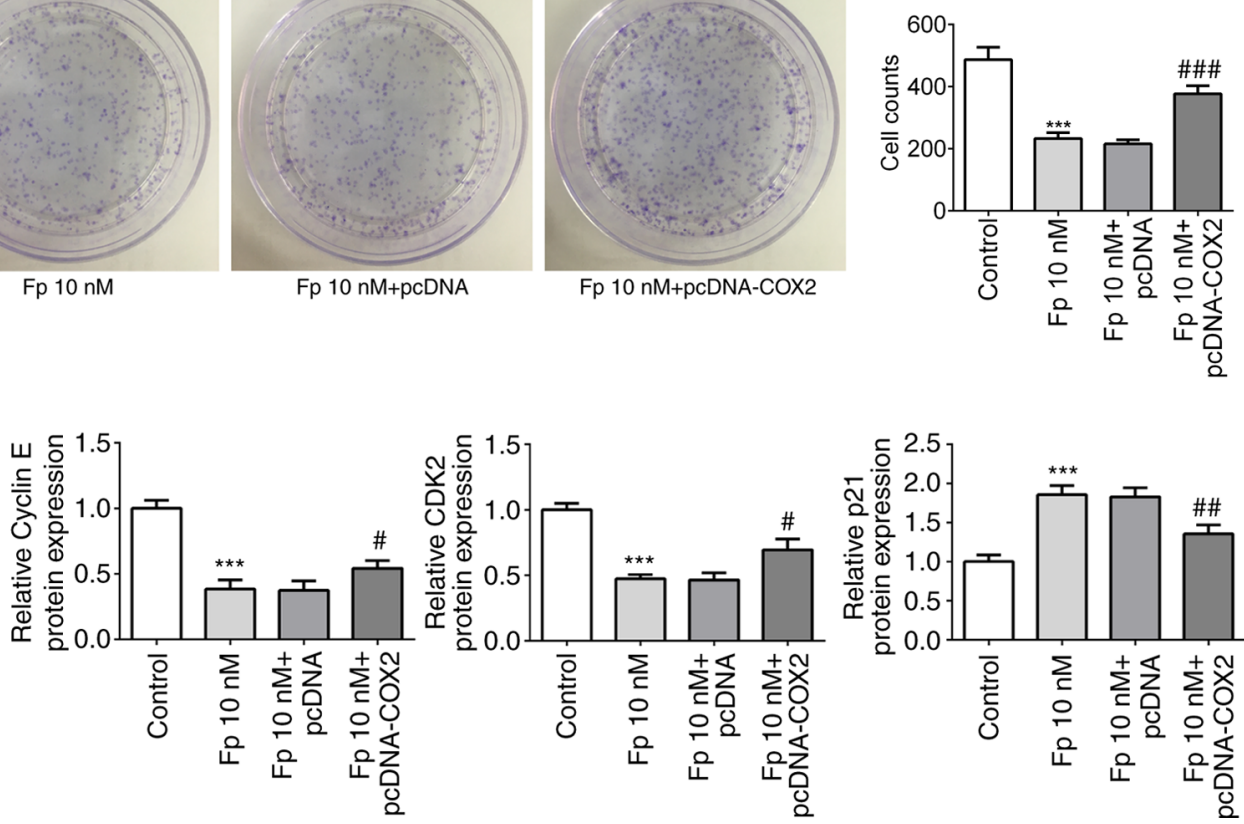

Figure 4. Fp suppresses cell proliferation. (A and B) Colony formation assay assessed the colony formation of SW620 cells in the four treatment groups ${ }^{* * * *} \mathrm{P}<0.001$ vs. control; ${ }^{\# \# \#} \mathrm{P}<0.001$ vs. Fp $10 \mathrm{nM}+$ pcDNA. (C) Apoptosis-related proteins in the different groups were examined via western blotting. ${ }^{* * *} \mathrm{P}<0.001$ vs. control. ${ }^{\#} \mathrm{P}<0.05,{ }^{\# \#} \mathrm{P}<0.01$ vs. Fp $10 \mathrm{nM}+$ pcDNA. Fp, flurbiprofen; CDK2, cyclin-dependent kinase 2; COX2, cyclooxygenase 2 .

These results suggested that flurbiprofen could inhibit the proliferation of colorectal cancer cells by inhibiting COX2.

Flurbiprofen promotes the apoptosis of colorectal cancer cells by inhibiting $\mathrm{COX} 2$. It has been reported that $\mathrm{COX} 2$ can inhibit apoptosis (32), therefore the present study investigated whether flurbiprofen has an effect on colorectal cancer cell apoptosis. The results indicated that the apoptosis of cells treated with flurbiprofen was significantly increased. However, in cells co-treated with flurbiprofen and COX2 overexpression vector, 
A
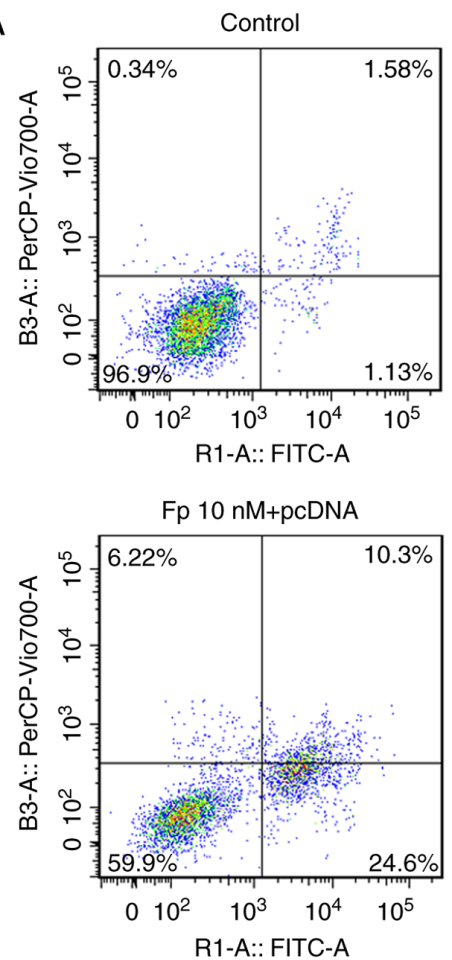

B

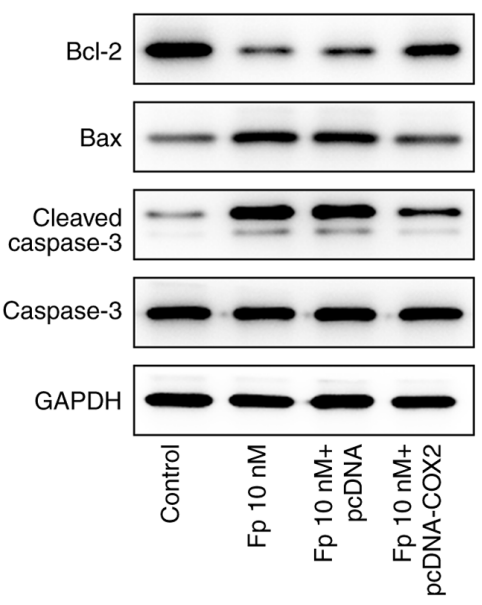

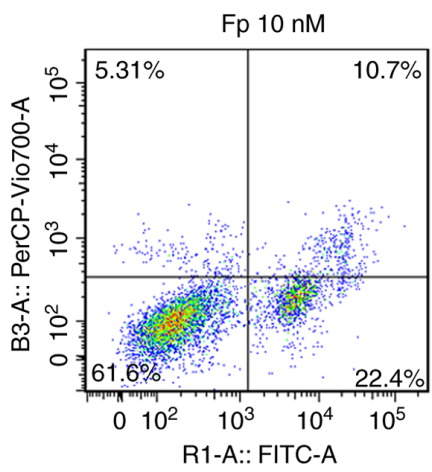
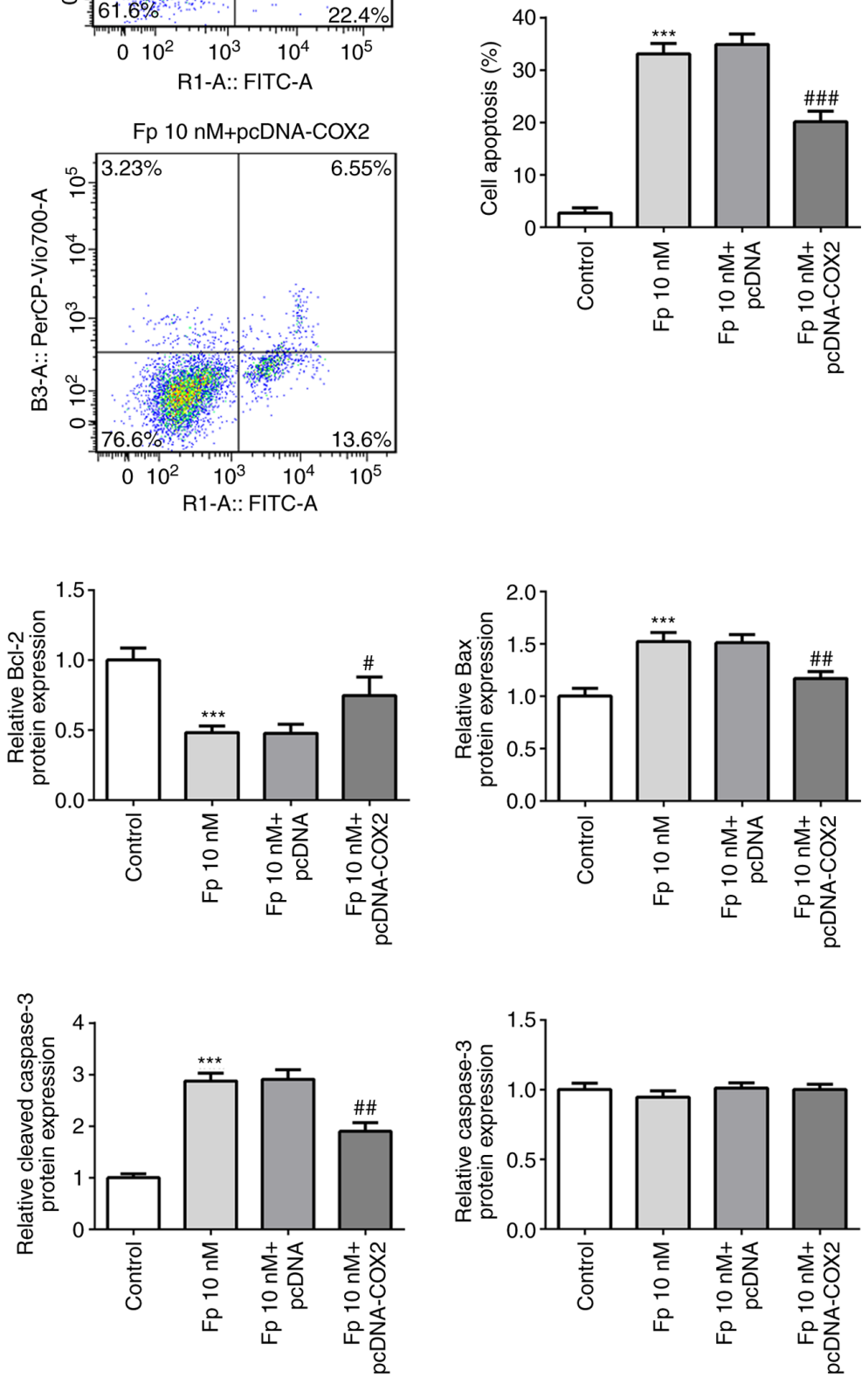

Figure 5. Fp induces cell apoptosis. (A) Cell apoptosis of SW620 cells was examined by flow cytometry analysis following COX2 overexpression and/or treatment with Fp. (B) Apoptosis-associated proteins were measured via western blot analysis in SW620 cells. ${ }^{* * * *} \mathrm{P}<0.001$ vs. control. ${ }^{\#} \mathrm{P}<0.05$, ${ }^{\# \#} \mathrm{P}<0.01,{ }^{\# \# "} \mathrm{P}<0.001$ vs. Fp $10 \mathrm{nM}+$ pcDNA. Fp, flurbiprofen; COX2, cyclooxygenase 2 .

the level of apoptosis was significantly reduced compared with in cells treated with flurbiprofen alone (Fig. 5A). Furthermore, the expression levels of apoptosis-associated proteins, including $\mathrm{Bcl} 2$, Bax, cleaved-caspase-3 and total caspase-3, were evaluated. The results demonstrated that flurbiprofen significantly decreased the expression of $\mathrm{Bcl} 2$ and significantly increased the expression of Bax and cleaved-caspase3, with no effect on total caspase-3 (Fig. 5B). However, following co-treatment with flurbiprofen and $\mathrm{COX} 2$ overexpression vector, the flurbiprofen-induced changes of Bcl2, Bax and cleaved-caspase-3 expression levels were significantly reversed.

Flurbiprofen inhibits invasion and migration of colorectal cancer cells by inhibiting COX2. The aforementioned data 
A

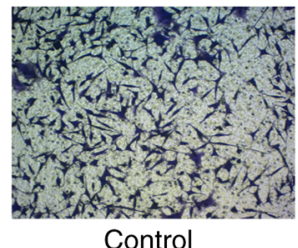

B
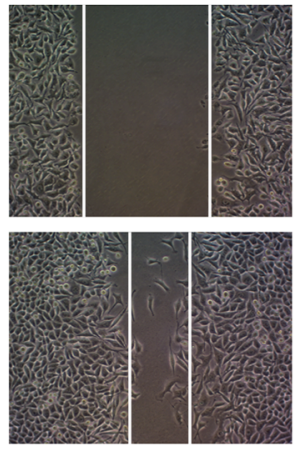

Control

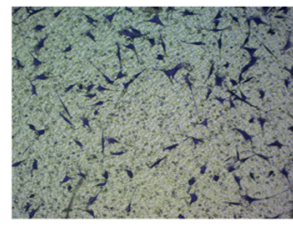

Fp $10 \mathrm{nM}$
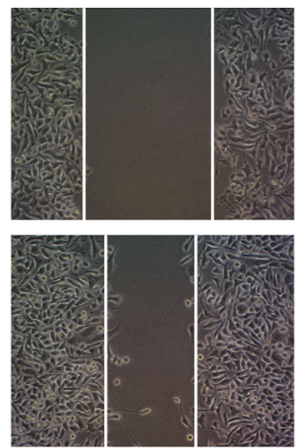

$\mathrm{Fp} 10 \mathrm{nM}$
Fp 10 nM+pcDNA
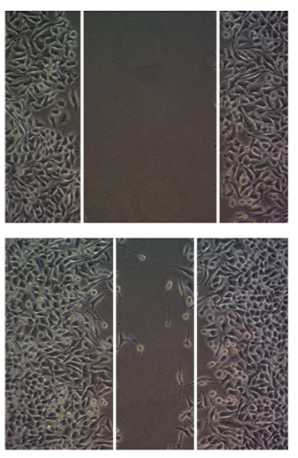

Fp 10 nM+pcDNA

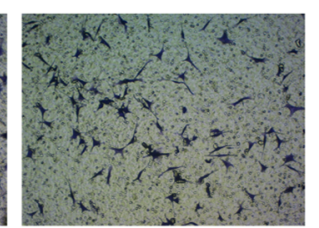

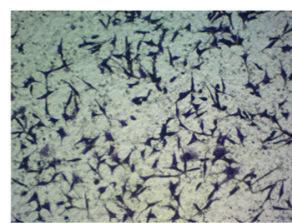

Fp 10 nM+pcDNA-COX2
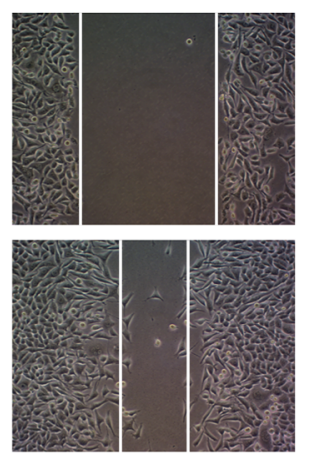

$\mathrm{Fp} 10 \mathrm{nM}+\mathrm{pcDNA}-\mathrm{COX} 2$
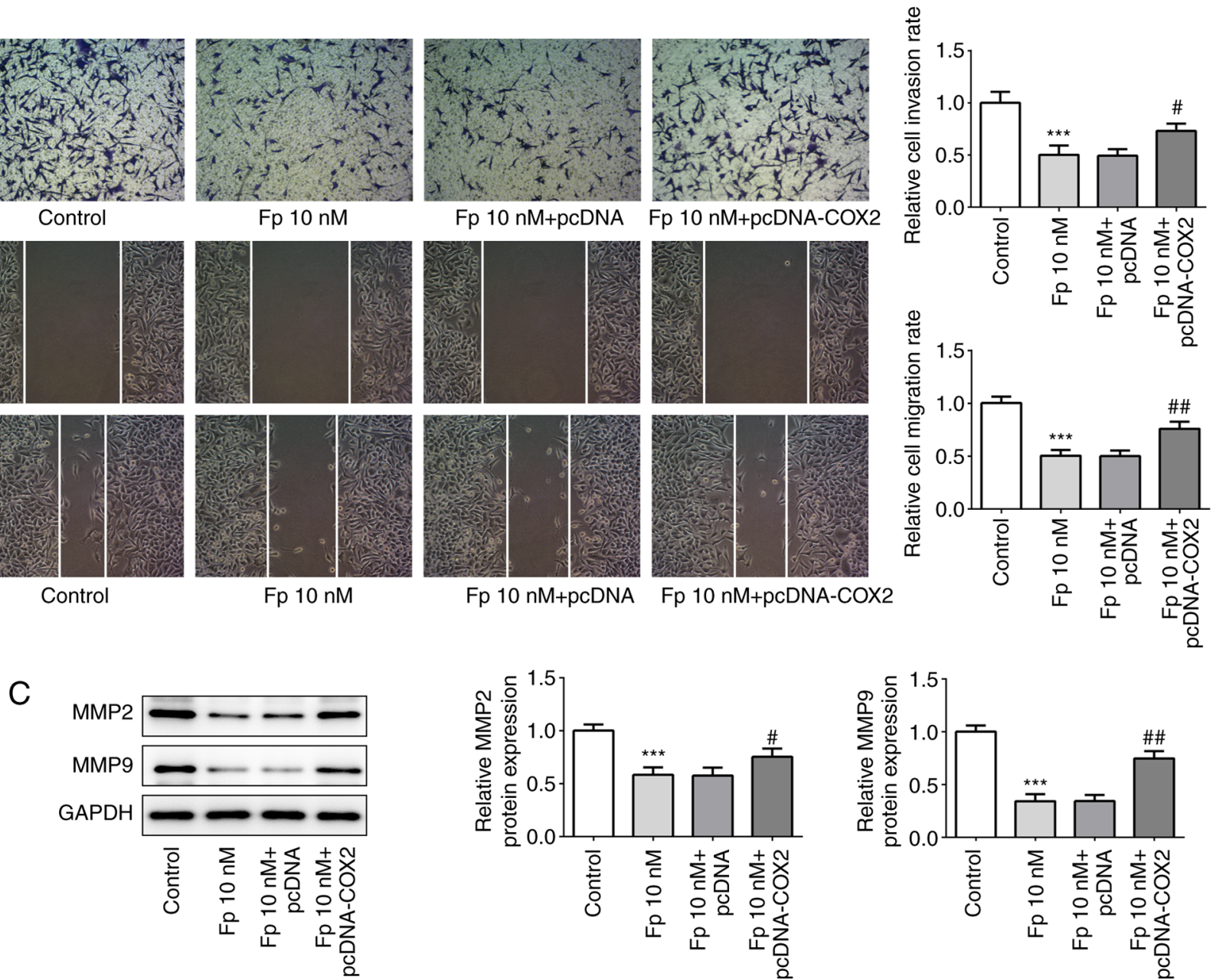

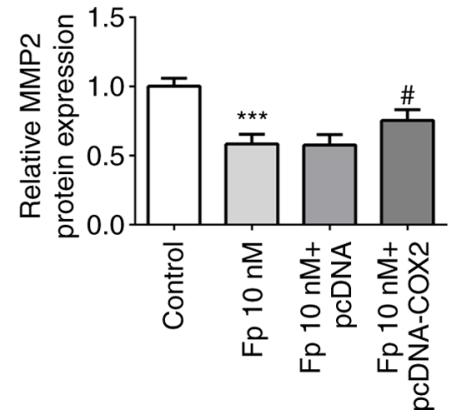

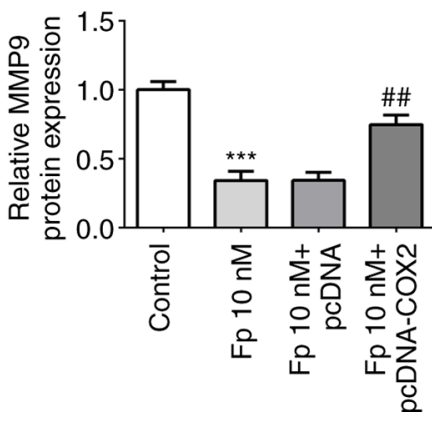

Figure 6. Fp suppresses cell invasion and migration. (A) Transwell (magnification, x100) and (B) wound healing (magnification, $\mathrm{x} 100$ ) assays were performed to assess cell invasion and migration following COX2 overexpression and/or treatment with Fp. (C) MMP2 and MMP9 protein expression levels were detected via western blotting. ${ }^{* * *} \mathrm{P}<0.001$ vs. control. ${ }^{\#} \mathrm{P}<0.05,{ }^{\# \#} \mathrm{P}<0.01$ vs. Fp $10 \mathrm{nM}+$ pcDNA. Fp, flurbiprofen; COX2, cyclooxygenase 2; MMP, matrix metalloproteinase.

demonstrated the effects of flurbiprofen on cell proliferation and apoptosis in colorectal cancer, therefore the effects of flurbiprofen on colorectal cancer cell invasion and migration were then examined. Transwell and wound healing assays with SW620 cells were performed (Fig. 6A and B). When the cells were treated with flurbiprofen, the invasion and migration abilities were significantly reduced compared with the control cells. However, when cells were co-treated with flurbiprofen and COX2 overexpression plasmid, the invasion and migration abilities of cells were significantly reversed compared with the effect of flurbiprofen alone. Since matrix metalloproteinase (MMP)2 and MMP9 are key proteins associated with invasion and migration (33), whether flurbiprofen effected MMP2 and MMP9 expression was then investigated. The western blotting results demonstrated that the expression levels of MMP2 and MMP9 were significantly downregulated by flurbiprofen. However, when cells were co-treated with flurbiprofen and COX2 overexpression plasmid, the expression levels of MMP2 and MMP9 were significantly increased compared with in cells treated with flurbiprofen alone (Fig. 6C). In summary, flurbiprofen inhibited the invasion and migration of colorectal cancer cells by inhibiting COX2.

\section{Discussion}

Colorectal cancer is one of the most common malignancies of the digestive system (10). The etiology of colorectal cancer includes high nutrition, low fiber diet, genetic factors, some chronic intestinal diseases with intestinal mucosal hyperplasia, and a molecular biological basis of gradual canceration of colorectal mucosal epithelium (34). In recent years, the incidence of colorectal cancer has rapidly increased due to people's high protein diet and a lack of physical exercise, as well as exposure to various pathogenic factors (8). The onset process of colorectal cancer is relatively unidentified and generally limited of specific clinical manifestations (35). The majority of patients at the early stage do not have obvious clinical symptoms, and patients at end-stage or with distant metastasis lose the opportunity of surgery (36). Certain patients with colorectal cancer can receive chemotherapy, although chemotherapy is not always effective and is prone to resistance (37). All in all, the recurrence rate is high and the majority of patients cannot tolerate. Therefore, finding new treatments is important.

The present data suggested that flurbiprofen inhibited colorectal cancer cell proliferation. Flurbiprofen has several 
advantages, including specific targeting, a quick onset, long duration and few side effects; therefore, it is widely used in the treatment of advanced analgesia, postoperative analgesia and cancer pain (12). Flurbiprofen is a non-steroidal intravenous drug that can inhibit COX1 and COX2 non-selectively (30). It has been reported that flurbiprofen can inhibit the growth of cervical cancer, and COX2 is also involved in this process (38). The current study demonstrated that flurbiprofen could inhibit the proliferation of colorectal cancer cells, and COX2 was involved in this process. As a non-selective inhibitor of $\mathrm{COX} 2$, the anticancer mechanism of flurbiprofen may be associated with the following aspects (39). First, specific targeting is a characteristic of flurbiprofen; it can inhibit tumor cell growth, but has little effect on normal cells (40). Secondly, flurbiprofen inhibits the expression of $\mathrm{COX} 2$, thus decreasing prostaglandin E2 and thromboxane A2, and even reducing vascular endothelial growth factor and fibroblast growth factor to inhibit tumor angiogenesis (27). Thirdly, it promotes the apoptosis of tumor cells (41); and finally, it enhances the effect of tumor immunotherapy (42).

In conclusion, the present study demonstrated that flurbiprofen decreased COX2 expression in colorectal cancer, and that flurbiprofen also inhibited the inflammation response, proliferation, invasion and migration, and promoted the apoptosis of colorectal cancer cells. Therefore, flurbiprofen may be a useful therapeutic method for colorectal cancer. However, the absence of the pcDNA-COX2 only group (i.e. without $10 \mathrm{nM}$ flurbiprofen) in several assays is a limitation of the current study, resulting in a lack of comparative explanation for the function of flurbiprofen in colorectal cancer.

\section{Acknowledgements}

Not applicable.

\section{Funding}

The present study was supported by Jinhua Traditional Chinese Medicine Research Project (grant no. 2017jzk04).

\section{Availability of data and materials}

The datasets used and/or analyzed during the current study are available from the corresponding author on reasonable request.

\section{Authors' contributions}

$\mathrm{XW}$ wrote the majority of the manuscript. XY and $\mathrm{YZ}$ performed the experiments. XW and FJ analyzed and interpreted the data. All authors read and approved the final manuscript.

\section{Ethics approval and consent to participate}

Not applicable.

\section{Patient consent for publication}

Not applicable.

\section{Competing interests}

The authors declare that they have no competing interests.

\section{References}

1. Cho YA, Lee J, Oh JH, Chang HJ, Sohn DK, Shin A and Kim J: Inflammatory dietary pattern, IL-17F genetic variant, and the risk of colorectal cancer. Nutrients 10: 724, 2018.

2. Xue J, Ge X, Zhao W, Xue L, Dai C, Lin F and Peng W: PIPKI $\gamma$ regulates CCL2 expression in colorectal cancer by activating AKT-STAT3 signaling. J Immunol Res 2019: 3690561, 2019.

3. Xu M, Chen X, Lin K, Zeng K, Liu X, Pan B, Xu X, Xu T, $\mathrm{Hu} \mathrm{X}$, Sun L, et al: The long noncoding RNA SNHG1 regulates colorectal cancer cell growth through interactions with EZH2 and miR-154-5p. Mol Cancer 17: 141, 2018.

4. Lal N, White BS, Goussous G, Pickles OJ, Mason M, Beggs AD, Taniere P, Willcox BE, Guinney J and Middleton G: KRAS mutation and consensus molecular subtypes 2 and 3 are independently associated with reduced immune infiltration and reactivity in colorectal cancer. Clin Cancer Res 24: 224-233, 2018.

5. Liang Q, Ma D, Zhu X, Wang Z, Sun TT, Shen C, Yan T, Tian X, Yu T, Guo F, et al: RING-finger protein 6 amplification activates JAK/STAT3 pathway by modifying SHP-1 ubiquitylation and associates with poor outcome in colorectal cancer. Clin Cancer Res 24: 1473-1485, 2018.

6. Hannigan GD, Duhaime MB, Ruffin MT, Koumpouras CC and Schloss PD: Diagnostic potential and interactive dynamics of the colorectal cancer Virome. MBio 9: e2248-e2218, 2018.

7. Ricker CN, Hanna DL, Peng C, Nguyen NT, Stern MC, Schmit SL, Idos GE, Patel R, Tsai S, Ramirez V, et al: DNA mismatch repair deficiency and hereditary syndromes in latino patients with colorectal cancer. Cancer 123: 3732-3743, 2017.

8. Riley JM, Cross AW, Paulos CM, Rubinstein MP, Wrangle J and Camp ER: The clinical implications of immunogenomics in colorectal cancer: A path for precision medicine. Cancer 124: 1650-1659, 2018

9. Karuturi MS, Holmes HM, Lei X, Johnson M, Barcenas CH, Cantor SB, Gallick GE, Bast RC and Giordano SH: Potentially inappropriate medications defined by STOPP criteria in older patients with breast and colorectal cancer. J Geriatr Oncol 10: 705-708, 2019.

10. Subramanian S, Hoover S, Tangka FKL, DeGroff A, Soloe CS, Arena LC, Schlueter DF, Joseph DA and Wong FL: A conceptual framework and metrics for evaluating multicomponent interventions to increase colorectal cancer screening within an organized screening program. Cancer 124: 4154-4162, 2018.

11. Zhang L, Shu R, Zhao Q, Li Y, Yu Y and Wang G: Preoperative butorphanol and flurbiprofen axetil therapy attenuates remifentanil-induced hyperalgesia after laparoscopic gynaecological surgery: A randomized double-blind controlled trial. Br J Anaesth 117: 504-511, 2016.

12. Wobst I, Ebert L, Birod K, Wegner MS, Hoffmann M, Thomas D, Angioni C, Parnham MJ, Steinhilber D, Tegeder I, et al: R-flurbiprofen traps prostaglandins within cells by inhibition of multidrug resistance-associated protein-4. Int J Mol Sci 18: 68, 2016.

13. Wang Y,Zhang HB, Xia B, Wang GM and Zhang MY: Preemptive analgesic effects of flurbiprofen axetil in patients undergoing radical resection of esophageal carcinoma via the left thoracic approach. Chin Med J (Engl) 125: 579-582, 2012.

14. Ashraf Z, Alamgeer, Kanwal M, Hassan M, Abdullah S, Waheed M, Ahsan H and Kim SJ: Flurbiprofen-antioxidant mutual prodrugs as safer nonsteroidal anti-inflammatory drugs: Synthesis, pharmacological investigation, and computational molecular modeling. Drug Des Devel Ther 10: 2401-2419, 2016.

15. Zhou Y, Huang J, Bai Y, Li C and Lu X: Effects of preemptive analgesia with flurbiprofen ester on lymphocytes and natural killer cells in patients undergoing esophagectomy: A randomized controlled pilot study. Thorac Cancer 8: 649-654, 2017.

16. Wang D, Yang XL, Chai XQ, Shu SH, Zhang XL, Xie YH, Wei X, Wu YJ and Wei W: A short-term increase of the postoperative naturally circulating dendritic cells subsets in flurbiprofen-treated patients with esophageal carcinoma undergoing thoracic surgery. Oncotarget 7: 18705-18712, 2016. 
17. Otsuka N, Yataba I, Matsushita I, Matsumoto H, Hoshino Y and Terada Y: A minimal impact of long-term S-flurbiprofen plaster application on kidney function in osteoarthritis patients. Clin Exp Nephrol 21: 1060-1067, 2017.

18. Yin Y, Yi Y, Yu J, Sun X, Liu C and Xu F: Effects of flurbiprofen on serum level of interleukin-6, prostacyclin and corticosteroid A2 in patients with bone metastases of cancer. Oncol Lett 15: 1545-1548, 2018.

19. Ooki A, Del Carmen Rodriguez Pena M, Marchionni L, Dinalankara W, Begum A, Hahn NM, VandenBussche CJ, Rasheed ZA, Mao S, Netto GJ, et al: YAP1 and COX2 coordinately regulate urothelial cancer stem-like cells. Cancer Res 78: 168-181, 2018.

20. Aich A, Wang C, Chowdhury A, Ronsör C, Pacheu-Grau D, Richter-Dennerlein R, Dennerlein S and Rehling P: COX16 promotes COX2 metallation and assembly during respiratory complex IV biogenesis. Elife 7: e32572, 2018.

21. Basudhar D, Glynn SA, Greer M, Somasundaram V, No JH, Scheiblin DA, Garrido P, Heinz WF, Ryan AE, Weiss JM, et al: Coexpression of NOS2 and COX2 accelerates tumor growth and reduces survival in estrogen receptor-negative breast cancer. Proc Natl Acad Sci USA 114: 13030-13035, 2017.

22. Sun Y, Dai H, Chen S, Zhang Y, Wu T, Cao X, Zhao G, Xu A, Wang $\mathbf{J}$ and Wu L: Disruption of chromosomal architecture of cox 2 locus sensitizes lung cancer cells to radiotherapy. Mol Ther 26: 2456-2465, 2018.

23. Jiang WW, Wang QH, Peng P, Liao YJ, Duan HX, Xu M, Li Y and Zhang PB: Effects of flurbiprofen axetil on postoperative serum IL-2 and IL-6 levels in patients with colorectal cancer. Genet Mol Res 14: 16469-16475, 2015.

24. Wirrig EE, Gomez MV, Hinton RB and Yutzey KE: COX2 inhibition reduces aortic valve calcification in vivo. Arterioscler Thromb Vasc Biol 35: 938-947, 2015.

25. Yu J, Jiang L, Gao Y, Sun Q, Liu B, Hu Y and Han X: Interaction between BMSCs and EPCs promotes IUA angiogenesis via modulating PI3K/Akt/Cox2 axis. Am J Transl Res 10: 4280-4289, 2018.

26. Lee CW, Lin ZC, Hu SC, Chiang YC, Hsu LF, Lin YC, Lee IT, Tsai MH and Fang JY: Urban particulate matter down-regulates filaggrin via COX2 expression/PGE2 production leading to skin barrier dysfunction. Sci Rep 6: 27995, 2016.

27. Ooki A, Begum A, Marchionni L, VandenBussche CJ, Mao S, Max K and Hoque MO: Arsenic promotes the COX2/PGE2-SOX2 axis to increase the malignant stemness properties of urothelial cells. Int J Cancer 143: 113-126, 2018.

28. Marutha Muthu AK, Cheah PL, Koh CC, Chew MF, Toh YF and Looi LM: Cyclooxygenase-2 (COX2) expression in adenocarcinoma surpasses that of squamous cell carcinoma in the uterine cervix. Malays J Pathol 39: 251-255, 2017.

29. Livak KJ and Schmittgen TD: Analysis of relative gene expression data using real-time quantitative PCR and the 2(-Delta Delta C(T)) method. Methods 25: 402-408, 2001

30. Kim SR, Park JH, Lee ME, Park JS, Park SC and Han JA Selective COX-2 inhibitors modulate cellular senescence in human dermal fibroblasts in a catalytic activity-independent manner. Mech Ageing Dev 129: 706-713, 2008.
31. MacDowell KS, Marsá MD, Buenache E, Villatoro JML, Moreno B, Leza JC and Carrasco JL: Inflammatory and antioxidant pathway dysfunction in borderline personality disorder. Psychiatry Res 284: 112782, 2020.

32. Xiao J, Wang F, Lu H, Xu S, Zou L, Tian Q, Fu Y, Lin X, Liu L, Yuan $\mathrm{P}$, et al: Targeting the COX2/MET/TOPK signaling axis induces apoptosis in gefitinib-resistant NSCLC cells. Cell Death Dis 10: 777, 2019.

33. Shan ZG, Sun ZW, Zhao LQ, Gou Q, Chen ZF, Zhang JY, Chen W, Su CY, You N, Zhuang Y and Zhao YL: Up-regulation of TINAGL1 promotes gastric cancer growth and metastasis by regulating multiple MMPs expression. J Gastroenterol Hepatol: Jun 14, 2020 (Epub ahead of print). doi: 10.1111/jgh.15150.

34. Ji L, Chen S, Gu L and Zhang X: Exploration of potential roles of m6A regulators in colorectal cancer prognosis. Front Oncol 10: $768,2020$.

35. Shu X, Xiang YB, Rothman N, Yu D, Li HL, Yang G, Cai H, Ma X, Lan Q, Gao YT, et al: Prospective study of blood metabolites associated with colorectal cancer risk. Int J Cancer 143: 527-534, 2018.

36. Mojica CM, Glenn BA, Chang C and Bastani R: The relationship between neighborhood immigrant composition, limited english proficiency, and late-stage colorectal cancer diagnosis in california. Biomed Res Int 2015: 460181, 2015.

37. Butt J, Blot WJ, Teras LR, Visvanathan K, Le Marchand L, Haiman CA,Chen Y,BaoY,SessoHD,Wassertheil-SmollerS, etal: Antibody responses to streptococcus gallolyticus subspecies gallolyticus proteins in a large prospective colorectal cancer cohort consortium. Cancer Epidemiol Biomarkers Prev 27: 1186-1194, 2018.

38. Li H, Zhou J, Wei X, Chen R, Geng J, Zheng R, Chai J, Li F and Jiang S: miR-144 and targets, c-fos and cyclooxygenase-2 (COX2), modulate synthesis of PGE2 in the amnion during pregnancy and labor. Sci Rep 6: 27914, 2016.

39. Shiow LR, Favrais G, Schirmer L, Schang AL, Cipriani S Andres C, Wright JN, Nobuta H, Fleiss B, Gressens P and Rowitch DH: Reactive astrocyte COX2-PGE2 production inhibits oligodendrocyte maturation in neonatal white matter injury. Glia 65: 2024-2037, 2017.

40. Amrite AC and Kompella UB: Celecoxib inhibits proliferation of retinal pigment epithelial and choroid-retinal endothelial cells by a cyclooxygenase-2-independent mechanism. J Pharmacol Exp Ther 324: 749-758, 2008.

41. Duncan K, Uwimpuhwe H, Czibere A, Sarkar D, Libermann TA, Fisher PB and Zerbini LF: NSAIDs induce apoptosis in nonproliferating ovarian cancer cells and inhibit tumor growth in vivo. IUBMB Life 64: 636-643, 2012.

42. Hu JC, Chai XQ, Wang D, Shu SH, Magnussen CG, Xie LX and $\mathrm{Hu}$ SS: Intraoperative flurbiprofen treatment alters immune checkpoint expression in patients undergoing elective thoracoscopic resection of lung cancer. Med Princ Pract 29: 150-159, 2020.

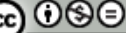

This work is licensed under a Creative Commons Attribution-NonCommercial-NoDerivatives 4.0 International (CC BY-NC-ND 4.0) License. 